\title{
Screening for genetic haemochromatosis in blood samples with raised alanine aminotransferase
}

\author{
M Bhavnani, D Lloyd, A Bhattacharyya, J Marples, P Elton, M Worwood
}

\begin{abstract}
Background-In the UK approximately 1 in 140 people are homozygous for the C282Y mutation of the HFE gene and are at risk from iron overload caused by genetic haemochromatosis (GH). Early detection can prevent organ damage secondary to iron deposition and increase life expectancy.

Aim-To screen for GH in all blood samples sent to the laboratory for routine liver function tests in which raised serum alanine aminotransferase (ALT) activity was detected.

Methods-ALT was measured in sera sent to the laboratory for routine liver function tests. In those samples found to have raised activity, transferrin saturation and ferritin were measured followed by genetic testing when transferrin saturation was increased.

Results-Of the 35069 serum samples assayed for routine liver function tests, $1490(4.2 \%)$ had raised ALT levels (>50 $u / 1)$. Transferrin saturation and serum ferritin concentrations were measured in these patient samples, and in 56 transferrin saturation was $>60 \%$. Further blood samples were requested from these patients for genetic testing: 33 samples were obtained. There were nine patients homozygous for the C282Y mutation of the HFE gene and three compound heterozygotes (heterozygous for both C282Y and H63D mutations).
\end{abstract}

Conclusions-The association of raised ALT activity and transferrin saturation of $>60 \%$ could provide a simple, cost effective method for detecting individuals with clinical haemochromatosis. Although many patients with GH may have been missed, this study suggests that the clinical penetrance of the disorder may be much lower than is generally supposed and that genetic screening will identify many people who may never develop clinical haemochromatosis.

(Gut 2000;46:707-710)

Keywords: haemochromatosis; alanine aminotransferase

Genetic haemochromatosis $(\mathrm{GH})$ is one of the most common genetic disorders in Northern Europe with a prevalence of approximately 1 in 300 in parts of Northern Europe. ${ }^{1}$ This autosomal recessive disorder of iron metabolism results in iron being continuously absorbed from the upper small intestine despite increasing total body iron stores. Excess iron deposition leads to organ damage, in particular in the liver (cirrhosis, hepatocellular carcinoma), pancreas (diabetes mellitus), heart (cardiomyopathy and heart failure), joints (arthralgia and arthritis), and pituitary (hypopituitarism). The non-specific nature of the clinical manifestations means that the disorder is often not diagnosed until life threatening complications develop. ${ }^{2}$

Diseases of the liver are a major cause of premature death in untreated $\mathrm{GH} .{ }^{3}$ If the diagnosis is made early, iron can be removed by repeated venesection and life expectancy is improved. When cirrhosis has developed, it is not reversible by treatment ${ }^{4}$ and although patients can live for extended periods they have a marked increased risk of developing hepatic cancer. $^{3}$

In clinical studies of patients with $\mathrm{GH}$, abnormal serum aminotransferase activity has been found in $65-75 \%$ of cases. ${ }^{56}$ George and colleagues $^{7}$ found abnormalities of serum aminotransferase in $48 \%$ of patients with $\mathrm{GH}$ diagnosed by liver biopsy, although half the patients with iron overload did not have raised aminotransferase activity. A number of studies have shown that the cause of mild liver enzyme abnormalities may be attributable to $\mathrm{GH}$ in at least 3\% of cases. ${ }^{8}$ Thus early detection and diagnosis of $\mathrm{GH}$ is crucial in patients presenting with liver enzyme abnormalities.

Screening for the early detection of GH has been advocated both in the general population $^{910}$ and in patients with liver disease, ${ }^{511}$ and the recent identification of the HFE gene has provided a specific genetic test for the disorder. ${ }^{12}{ }^{13}$ Recent data have shown that the frequency of the HFE mutation (C282Y) responsible for $\mathrm{GH}$ is higher than previously suspected, with about $15 \%$ of the UK population being carriers and 1 in 140 being homozygous. ${ }^{14-17}$ Compound heterozygotes for both C282Y and H63D account for about $3 \%$ of the general population.

We have determined the frequency of C282Y mutations of the HFE gene in a cohort of patients chosen from consecutive laboratory samples for biochemical screening and found to have a raised serum alanine aminotransferase ((ALT), EC 2.6.1.2.) level and an elevated transferrin saturation.

Subjects and methods

The study was approved by the local research ethics committee.

Abbreviations used in this paper: $\mathrm{GH}$, genetic haemochromatosis; ALT, alanine aminotransferase.

WN1 2NN, UK

mba@wigan-haem.prestel.co.u 
Table 1 Relationship between serum ferritin, transferrin saturation and mutation

\begin{tabular}{lllll}
\hline Genotype & $\begin{array}{l}\text { No of } \\
\text { patients }\end{array}$ & Age $(y)$ & Serum ferritin $\left(\mu g / l^{a}\right.$ & $\begin{array}{l}\text { Transferrin } \\
\text { saturation }(\%)^{b}\end{array}$ \\
\hline $\begin{array}{l}\text { Normal } \\
\text { Homozygous } \\
\text { for C282Y }\end{array}$ & 14 & $56(23-70)$ & $781(213-1560)$ & $71(61-82)$ \\
$\begin{array}{c}\text { Heterozygous } \\
\text { for C282Y }\end{array}$ & 2 & $57(43-70)$ & $1580(434-3292) \mathrm{p}=0.047^{\star}$ & $80(68-92) \mathrm{ns}$ \\
$\begin{array}{c}\text { Heterozygous } \\
\text { for H63D }\end{array}$ & 5 & $45(28-70)$ & $799(241-1357) \mathrm{ns}$ & $65(61-69) \mathrm{ns}$ \\
$\begin{array}{c}\text { Double } \\
\text { heterozygous }\end{array}$ & 3 & $49(40-67)$ & $2240(1450-6260) \mathrm{p}<0.02^{\star}$ & $77(74-82) \mathrm{ns}$ \\
\hline
\end{tabular}

Values are (mean (range)).

${ }^{a}$ Reference range: $\mathrm{M}: 20-284 \mu \mathrm{g} / 1, \mathrm{~F}: 8-186 \mu \mathrm{g} / 1$; ${ }^{\mathrm{b}}$ Reference range: $13-53 \%$.

*Significant difference compared with the normal genotype group.

Blood samples (35 069) were received from inpatients $(35 \%)$, outpatients $(24 \%)$, and GP patients $(41 \%)$ in whom routine liver function tests had been requested. Serum liver function tests, including ALT, were measured on an Olympus AU800 analyser using standard methodology. In those samples with an ALT $>50 \mathrm{u} / 1$ (reference range 5-45 u/l), serum iron, transferrin, and ferritin concentrations were measured. Serum iron and transferrin were analysed using a Cobas Mira analyser with ferene acetate reagent (Instrumentation Laboratory Ltd, Warrington, UK) and immunoturbidometry reagents (Dako Ltd, Cambridge, UK), respectively. Transferrin saturation was calculated as (serum iron $(\mu \mathrm{mol} / \mathrm{l}) /$ transferrin $(\mathrm{g} / \mathrm{l})) \times 4$. Microparticle enzyme immunoassay was used to determine serum ferritin concentration (Abbott Laboratory, USA).

Information on $\mathrm{GH}$ and the advantages of screening were given to those patients with a transferrin saturation $>60 \%$, directly or via their general practitioner or hospital consultants, and the genetic test was offered. Those not responding were re-contacted. Thirty three patients $(54 \%)$ responded and informed consent was obtained followed by blood sample collection for genetic testing. HFE mutations were detected by polymerase chain reaction and restriction enzyme digestion as described by Merryweather-Clarke and colleagues, ${ }^{18}$ with the primers for the $\mathrm{C} 282 \mathrm{Y}$ reaction being those described by Jackson and colleagues. ${ }^{19}$ The Mann-Whitney U test was used to compare the biochemical parameters in each genotype group and to assess the statistical significance of the biochemical response to treatment.

\section{Results}

Over the eight month study period 35069 blood samples were routinely screened for ALT activity as part of a biochemical profile; 1490 $(4.2 \%)$ of the samples were found to have an ALT activity of greater than $50 \mathrm{u} / 1$ and of these, $56(3.7 \%)$ patients had a transferrin saturation $>60 \%$. Eight patients died before further studies could be undertaken, two from refractory congestive cardiac failure, one each from carcinoma of the pancreas and cerebrovascular accident, and four from alcoholic liver disease with related complications. A postmortem examination was performed in two of the latter cases confirming the clinical diagnosis of alcoholic liver disease. Further blood samples for HFE genotyping were requested from the 48
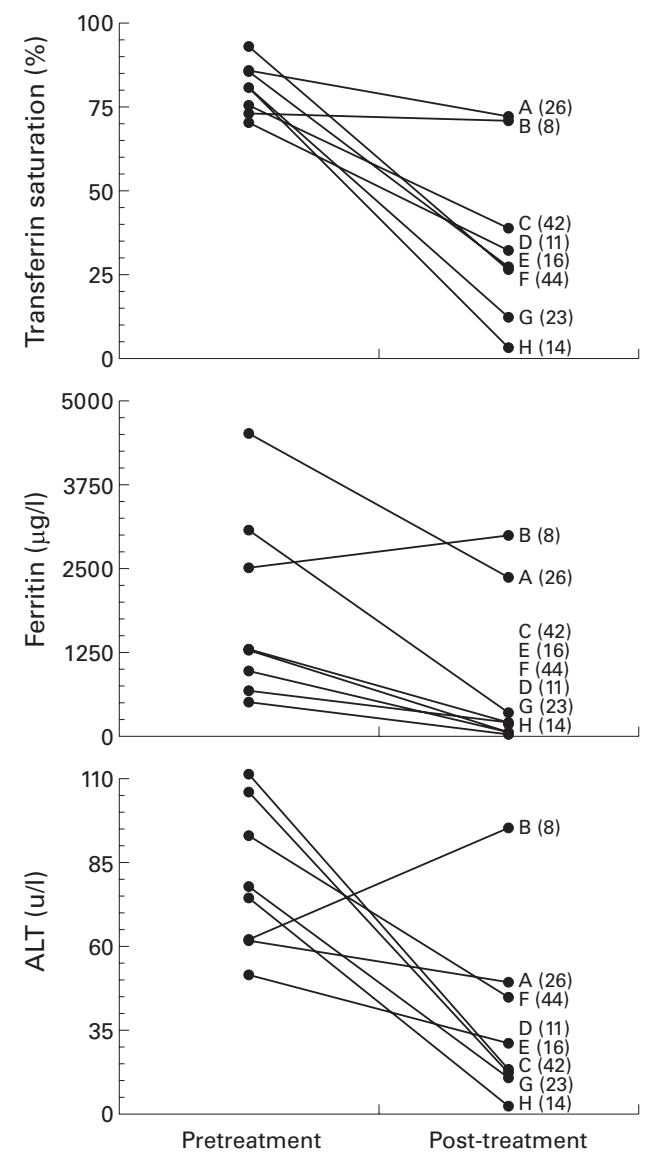

Figure 1 Serum transferrin saturation, ferritin, and alanine aminotransferase (ALT) levels in patients homozygous for C282Y before and after treatment with venesection. Units of blood venesected are given in parentheses.

patients with increased transferrin saturation. Five patients or their doctors declined to have HFE genotyping and no response was obtained from a further 10 individuals; thus 33 samples were received.

After HFE genotyping nine patients were found to be homozygous for the C282Y mutation of the HFE gene and none for H63D. Two were heterozygous for the C282Y mutation; five for H63D and a further three were compound heterozygotes (C282Y/H63D). The C282Y and H63D mutations were not present in 14 cases. Table 1 shows the relationship between serum ferritin, transferrin saturation, and the HFE genotype. No significant difference was found in terms of age or serum transferrin saturation between patients with the normal and mutant HFE genotypes. Serum ferritin was increased in patients homozygous for C282Y ( $p=0.05)$ and also in H63D heterozygotes $(p<0.02)$ but in these latter patients this is likely to be an artefact from the selection process and the small study size.

Liver function tests in the C282Y homozygotes and heterozygotes were essentially normal, apart from mildly raised ALT and gamma glutamyl transpeptidase values in contrast with patients with normal HFE genotypes who exhibited grossly abnormal liver function tests.

Of the nine C282Y homozygotes, eight have been treated and followed up for 15-20 
Table 2 Clinical details of C282Y homozygotes (all males)

\begin{tabular}{|c|c|c|c|c|c|}
\hline Patient; age & Reason for LFTs request & Clinical conditions & $\begin{array}{l}\text { Family history (1st degree } \\
\text { relatives) }\end{array}$ & $\begin{array}{l}\text { Alcohol intake } \\
\text { (units/week) }\end{array}$ & $\begin{array}{l}\text { Units of blood } \\
\text { venesected) (iron } \\
\text { removed }(g))^{\star}\end{array}$ \\
\hline A; $49 \mathrm{y}$ & $\begin{array}{l}\text { Routine test from } \\
\text { diabetic clinic }\end{array}$ & IDDM & No siblings & 84 & $26(6.5)$ \\
\hline B; $70 \mathrm{y}$ & $\begin{array}{l}\text { Hypertensive routine } \\
\text { test (GP) }\end{array}$ & IHD, hypertension & 1 sister $\mathrm{C} 282 \mathrm{Y}+/+$ & 0 & $8(2)$ \\
\hline C; $50 \mathrm{y}$ & Routine test (GP) & Depression & $\begin{array}{l}\text { No iron overload detected in } \\
\text { siblings }\end{array}$ & 20 & \\
\hline $\mathrm{D} ; 44 \mathrm{y}$ & Routine test (GP) & Backache, arthritis & No siblings & 2 & $11(2.75)$ \\
\hline $\mathrm{E} ; 48 \mathrm{y}$ & Routine test (GP) & Knee replacement & $\begin{array}{l}\text { No iron overload detected in } \\
\text { siblings }\end{array}$ & 48 & $16(4.0)$ \\
\hline F; $54 \mathrm{y}$ & $\begin{array}{l}\text { Tired routine test } \\
(\mathrm{GP})\end{array}$ & IDDM & $\begin{array}{l}1 \text { cousin } \mathrm{C} 282 \mathrm{Y}+/+ \text {, no } \\
\text { siblings }\end{array}$ & 50 & $44(11 \mathrm{~g})$ \\
\hline $\mathrm{G} ; 61 \mathrm{y}$ & Routine test (GP) & Fit & $\begin{array}{l}\text { No iron overload detected in } \\
\text { siblings }\end{array}$ & 8 & $23(5.75)$ \\
\hline $\mathrm{H} ; 51 \mathrm{y}$ & Routine test (GP) & $\begin{array}{l}\text { Arthritis, alcohol } \\
\text { excess }\end{array}$ & & 154 & $14(3.5)$ \\
\hline
\end{tabular}

^Assuming 1 unit $(500 \mathrm{ml})$ of blood contains $250 \mathrm{mg}$ of iron.

LFTs, liver function tests; IHD, ischaemic heart disease; IDDM, insulin dependent diabetes mellitus.

months. One patient (B) was diagnosed aged 70 years and has ischaemic heart disease. $\mathrm{He}$ was observed for a period of three months, then venesected by 1 unit $(500 \mathrm{ml})$ per month for three months but as his serum ferritin and ALT continued to rise (see fig 1) he has been started on a weekly venesection programme. All of the other patients have been venesected at weekly intervals, with removal of $3-11 \mathrm{~g}$ of iron (assuming that $500 \mathrm{ml}$ of blood contains 250 $\mathrm{mg}$ of iron). Clinical details of the patients are presented in table 2 . Two of eight patients had insulin dependent diabetes at presentation and three of eight had non-specific seronegative arthritis. Venesection has made no difference to the severity of the diabetes or arthritis.

Figure 1 shows the response to venesection of serum ALT, ferritin, and transferrin saturation. There was a reduction in serum ferritin by $75 \%(\mathrm{p}<0.03)$, in transferrin saturation by $62 \%(\mathrm{p}<0.003)$ and a reduction in ALT activity by $65 \%(\mathrm{p}<0.004)$.

\section{Discussion}

Genetic haemochromatosis is one of the commonest inherited metabolic disorders in populations of Northern European origin but is underdiagnosed because of its non-specific features (for example fatigue, arthritis, diabetes, cardiac or liver dysfunction, impotence, and amenorrhoea). A simple treatment (phlebotomy) is available and effective if instituted before organ damage has occurred. ${ }^{420}$ Considerable discussion about the efficacy and feasibility of population screening for $\mathrm{GH}$ has therefore taken place. Measurement of serum transferrin saturation is considered to be the best initial screening test ${ }^{21}$ although there is a continuing debate as to the best cut off level. However, a fasting transferrin saturation of more than $60 \%$ is considered by many as most appropriate. $^{21} 22$ George and colleagues measured random serum transferrin saturation in 1194 patients where a transferrin saturation of more than $55 \%$ gave few false positives and a positive predictive value of $24-43 \% .^{23}$ More recently a value of $45 \%$ has been suggested. ${ }^{24}$ However, Haddow and Ledue ${ }^{22}$ considered that lowering the cut off point by $5 \%$ or $10 \%$ would result in a marked decrease in specificity with no guaranteed improvement in sensitivity and therefore we have selected $60 \%$ as our cut off point.

In this study we used an increase in ALT as a method of selecting patients for screening for GH. Many iron loaded patients with haemochromatosis do not have significant liver disease or an elevated $\mathrm{ALT}^{7}$ and so it is likely that a number of homozygotes were missed. However, as nine homozygotes were detected by this method, in the early stages of their disease, and will probably now have a normal life span, we feel that this method is a valuable way of targeted screening for affected individuals. Following venesection there was a decrease in serum ALT in seven of the eight patients.

In the 1970 s, the association of haemochromatosis and the HLA-A locus on the short arm of chromosome 6 was identified..$^{25}$ This gene is a HLA class I-like gene situated approximately $4.5 \mathrm{Mb}$ from HLA-A on chromosome 6 . In the UK a change in a single amino acid (C282Y) was found in $95 \%$ of GH chromosomes compared with about $6 \%$ in patients from the general population. ${ }^{13} \mathrm{Ho}-$ mozygosity for the C282Y mutation is strongly associated with clinically diagnosed hereditary haemochromatosis. ${ }^{26}$ A second mutation, H63D, has also been described but the association between H63D and hereditary haemochromatosis is less clear. Homozygosity for $\mathrm{H} 63 \mathrm{D}$ is three to four times more common in the general population than for $\mathrm{C}_{2} 82 \mathrm{Y}^{27}$ but rare among subjects with a clinical diagnosis of haemochromatosis. In subjects with clinically diagnosed hereditary haemochromatosis who are heterozygous for C282Y, most $(77 \%)$ also carry H63D, suggesting a role for this mutation in disease causation. ${ }^{28}$ In our study we found three such double heterozygotes who had elevated serum ferritin levels but these patients have not been venesected and their degree of iron loading is unknown. The ability to track the high risk genotype in relatives of probands on the basis of HLA typing has permitted the recognition of characteristic clinical features and distinction between homozygotes and heterozygotes. ${ }^{29-31}$ Among subjects with 
hereditary haemochromatosis, family studies indicate that about $50 \%$ of women and $50-75 \%$ of men will develop clinical manifestations related to iron overload. ${ }^{32}$ HLA typing has now been largely replaced by analysis of HFE mutations.

In our study, of 35069 patients screened 56 where found to have increased transferrin saturation and raised ALT levels and of the 33 patients in this group tested, nine C282Y homozygotes and three compound C282Y/ H63D heterozygotes where identified. Given that in the general UK population homozygosity for the C282Y and compound heterozygosity for the $\mathrm{C} 282 \mathrm{Y} / \mathrm{H} 63 \mathrm{D}$ mutations are 1 in 140 and 3 in 100 respectively, 250 homozygotes and 1052 compound heterozygotes should have been found if all had raised ALT activity. George and colleagues ${ }^{7}$ found that only $48 \%$ of their patients with haemochromatosis had elevated serum ALT. Thus in our study, if approximately half of the homozygotes had not been detected at least 125 affected individuals would have been found. The actual number detected was considerably lower, suggesting that the clinical penetrance of both genotypes is far lower than is generally supposed ${ }^{8}$ and supports an assessment of patient numbers and C282Y homozygote frequency in Jersey ${ }^{17}$ and the analysis of death certificates in the USA. ${ }^{33}$ A recent study by Willis and colleagues ${ }^{34}$ showed that C282Y homozygosity was not under-represented in an elderly male population, also suggesting that life threatening haemochromatosis related disease may not occur in many C282Y homozygotes.

In those patients found to have a raised ALT, the cost of screening with transferrin saturation and follow up when appropriate with ferritin and genetic testing was $£ 1400$. This represents a cost of $£ 117$ per patient identified as homozygous for the $\mathrm{C} 282 \mathrm{Y}$ or compound mutations.

The diagnosis of GH can now be made with a high degree of confidence in a given individual with biochemical evidence of iron overload and an abnormal genotype. Thus a combination of an initial transferrin saturation screen followed by genetic testing when appropriate would now seem to offer a reliable cost effective algorithm for detecting $\mathrm{GH}$ in subjects with liver disease. This approach when applied to the present study detected nine patients (from the 33 patients genetically tested) in whom $\mathrm{GH}$ had not previously been identified. Subsequent therapeutic intervention will undoubtedly extend their life expectancy. The intervention could be further extended by using the patients as index cases for family studies.

1 Worwood M. Genetics of haemochromatosis. Baillieres Clin Haematol 1994;7:903-18.

2 Bothwell TH, Charlton RW, Motulsky AG. HaemochromaBothwell TH, Charlton RW, Motulsky AG. Haemochromatosis. In: Scriver CR, Beaudet AL, Sly WS, Valle D eds. The
metabolic and molecular basis of inherited disease. New York: metabolic and molecular basis of

Mcgraw-Hill, 1995:2237-69.
Niederau C, Strohymeyer G, Stremmel W. Epidemiology, clinical spectrum and prognosis of hemochromatosis. Adv Exp Med Biol 1994;356:293-302.
4 Niederau C, Fisher R, Purschel A, et al. Long-term survival in patients with hereditary haemochromatosis. Gasteroenterin patients with hereditary
ology 1996;110:1107-19.

5 Lin E, Adams PC. Biochemical liver profile in hemochromatosis. F Clin Gastroenterol 1991;13:316-20.

6 Adams PC, Deugnier Y, Moirand R, et al. The relationship between iron overload, clinical symptoms, and age in 410 patients with genetic hemochromatosis. Hepatology 1997; 25:162-6.

7 George DK, Fletcher LM, Monk CD, et al. Is hepatic iron the cause of raised transaminases in haemochromatosis. Hepatology 1998;28:421A.

8 Witte DL. Mild liver enzyme abnormalities: eliminating haemochromatosis as cause. Clin Chem 1997;43:1535-8.

9 Baer DM, James MD, Simons JL, et al. Haemochromatosis screening in asmptomatic ambulatory men 30 years of age and older. Am F Med 1995;98:464-8.

0 Waldron T. CDC recommends routine screening for 'iron overload'. Med Tribune 1997;38:1.

11 Herrer JL. Abnormal liver enzyme levels. Clinical evaluation in asymptomatic patients. Postgrad Med 1993;93:119-20.

12 Feder JN, Gnirke A, Thomas W, et al. A novel MHC class-1 gene is mutated in patients with hereditary haemochromatosis. Nat Genet 1996;13:399-408.

13 Worwood M, Shearman JD, Wallace DE, et al. A simple genetic test identifies $90 \%$ of UK patients with haemochrogenetic test identifies $90 \%$ of UK patients with haemochro-
matosis. The UK Haemochromatosis Consortium. Gut 1997;41:841-4.

14 Murphy S, Curran MD, McDougall N, et al. High incidence of the C282Y mutation in the HFE gene in the Irish population-implications for haemochromatosis. Tissue Antigens 1998;52:484-8.

15 Willis G, Jenning BA, Goodman E, et al. A high prevalence of the HLA-H 845A mutations in haemochromatosis patients and the normal population in eastern England. Blood Cells Molecules 1997;23:288-91.

16 Mullighan CG, Bunce M, Fanning GC, et al. A rapid method of haplotyping HFE mutations and linkage disequilibrium in a Caucasoid population. Gut 1998;42: 566-9.

17 Merryweather-Clarke AT, Worwood M, et al. The effect of HFE mutations on serum ferritin and transferrin saturation in the Jersey population. Br f Haematol 1998;101:36973 .

18 Merryweather-Clarke AT, Pointon JJ, Shearman JD, et al. Global prevalence of putative haemochromatosis mutations. F Med Genet 1997;34:275-8.

19 Jackson HA, Bowen DJ, Worwood M. Rapid genetic screening for haemochromatosis using heteroduplex technology. BrF Haematol 1997;98:856-9.

20 Witte DL, Crosby WH, Edwards CQ, et al. Practice Guideline Development Task Force of the College of American Pathologists: Hereditary Haemochromatosis. Clin Chim Acta 1996;245:139-200

21 Edwards CQ, Kushner JP. Screening for haemochromatosis. N Engl f Med 1993;328:1616-20.

22 Haddow JE, Ledue TB. Preventing manifestations of hereditary haemochromatosis through population based screening. F Med Screen 1994;1:16-21.

23 George DK, Evans RM, Crofton RW, Gunn IR. Testing for haemochromatosis in the diabetic clinic. Ann Clin Biochem 1995;32;521-6.

24 McLaren CE, McLachlan GJ, Halliday JW, et al. Distribution of transferrin saturation in an Australian population: relevance to the early diagnosis of hemochromatosis. Gastroenterology 1998;114:543-9.

25 Simon M, Bourel M, Fauchet R, Genet B. Association of HLA-A3 and HLA-B14 antigens with idiopathic haemochromatosis. Gut 1976;17:332-4.

26 Worwood M. Inborn errors of metabolism: iron. Br Med Bull 1999;55:556-67..

27 Bradley LA, Johnson DD, Palomaki GE, Haddow JE, Robertson NH, Ferrie RM. Hereditary haemochromatosis mutation frequencies in the general population. $\mathcal{F} \mathrm{Med}$ Screen 1998;5:34-6.

28 Beutler E. Genetic irony beyond haemochromatosis: clinical effects of HLA-H mutations. Lancet 1998;349;296-7.

29 Cartwright GE, Edwards CQ, Kravitz K, et al. Hereditary haemochromatosis: phenotypic expression of the disease. $N$ Engl f Med 1979;301:175-9.

30 Basset ML, Halliday JW, Powell LW. HLA typing in idiopathic haemochromatosis: distinction between homozygotes and heterozygotes with biochemical expression. Hepatology 1981;1:120-6.

31 Adams PC. Prevalence of abnormal iron studies in heterozygotes for hereditary haemochromatosis: an analysis of 255 heterozygotes. Am $\mathcal{F}$ Haematol 1994;45:146-9.

32 Bradley LA, Haddow JE, Palomaki GE. Population screening for haemochromatosis: expectations based on a study of relatives of symptomatic probands. $\mathcal{F}$ Med Screen 1996;3: 171-7.

33 Yang QH, McDonnell SM, Khoury MJ, et al. Hemochromatosis-associated mortality in the United Hemochromatosis-associated mortality in the United mortality data. Ann Intern Med 1998;129:946-53.

34 Willis G, Wimperis J, Smith K, et al. Haemochromatosis gene C282Y homozygotes in an elderly male population. Lancet 1999;354:221. 